\title{
Seismicity characteristics before the 2003 Chengkung, Taiwan, earthquake
}

\author{
Yih-Min $\mathrm{Wu}^{\mathrm{a}, *}$, Chien-Chih Chen ${ }^{\mathrm{b}}$, Li Zhao ${ }^{\mathrm{c}}$, Chien-Hsin Chang ${ }^{\mathrm{d}}$ \\ a Department of Geosciences, National Taiwan University, No. 1, Sec. 4th, Roosevelt Rd., Taipei 10617, Taiwan \\ b Department of Earth Sciences and Institute of Geophysics, National Central University, Jhongli 320, Taiwan \\ c Institute of Earth Sciences, Academia Sinica, Nankang, Taipei 115, Taiwan \\ d Central Weather Bureau, Taipei 100, Taiwan
}

\section{A R T I C L E I N F O}

\section{Article history:}

Received 24 October 2007

Received in revised form 5 June 2008

Accepted 5 June 2008

Available online 14 June 2008

\section{Keywords:}

Earthquake

Seismicity

Seismic quiescence

$b$-values

Earthquake precursors

\begin{abstract}
A B S T R A C T
We investigate the variations in seismicity pattern in the Taiwan region before the 2003 Chengkung, Taiwan, earthquake $\left(M_{\mathrm{w}}=6.8\right)$ by calculating the standard normal deviate of the $Z$-values and $b$-values from the Gutenberg-Richter relation. The Mogi donut-shaped variations in the seismicity can be identified in the $Z$-value map surrounding the Chengkung earthquake source region. Noticeable decreases in the $b$-values have also been found around the mainshock region before the Chengkung event. The relatively lowseismicity rate and the decrease in the $b$-values may be the precursory phenomena associated with the quiescence in overall seismicity and the activation of moderate-sized events occurred around the mainshock region before the Chengkung event.
\end{abstract}

Crown Copyright @ 2008 Published by Elsevier B.V. All rights reserved.

\section{Introduction}

Taiwan is located on the western Circum-Pacific seismic belt. Off the east coast, the Philippine Sea plate plunges northward under the Eurasian plate along the Ryukyu trench, whereas the Eurasian plate subducts eastward beneath the Philippine Sea plate off the southern tip of the island of Taiwan (Tsai et al., 1977; Wu, 1978). Tectonically, most of the Taiwan region is under NW-SE compression with a convergence rate of about $8 \mathrm{~cm} /$ year (Yu et al., 1997). The complex pattern in which these two plates interact has resulted in many highly complicated regional geological features and active seismicity. Fig. 1 shows the tectonic environment in the region and the distribution of the earthquakes of $M \geq 3.0$ between 1991 and 2006 .

Based on the tectonics and seismic characteristics, the Taiwan region can be classified into four different seismogenic zones ( $\mathrm{Wu}$ and Chen, 2007): (A) Western Seismic Zone: located within the Eurasia Plate (Fig. 1). Most of the earthquakes in this zone can be associated with active faults; (B) Southwestern Seismic Zone: located mainly in the South China Sea block of the Eurasian Plate. In terms of seismic activity, this is the least active zone among the four; (C) Northeastern Seismic Zone: associated with the Ryukyu subduction system and shows high seismicity with occasional damaging earthquakes (Wang, 1998); (D) Southeastern Seismic Zone: mainly caused by the collision of the Eurasia Plate and the Luzon island arc on the Philippine Sea Plate. Most of the seismic activity in the Taiwan region, including many large earthquakes, occurs in this area (Wang, 1998).

\footnotetext{
* Corresponding author. Tel.: +88622362 0054; fax: +886223644625.

E-mail address: drymwu@ntu.edu.tw (Y.-M. Wu).
}

The existence of earthquake precursors is a controversial but important issue. Among the various kinds of reported precursors, seismic quiescence (Mogi, 1979; Wyss and Habermann, 1988; Wiemer and Wyss, 1994; Huang et al., 2001; Huang and Nagao, 2002; Huang, 2004; Wu and Chiao, 2006) and activation (Chen, 2003; Huang, 2006b; Huang et al., 2002; Keilis-Borok and Kossobokov, 1990) are two that have received considerable attention. The Chengkung $M_{\mathrm{w}} 6.8$ earthquake (Wu et al., 2006; Kuochen et al., 2007) on December 10, 2003, in eastern Taiwan has been the largest near-shore or on-land event since the 1999 Chi-Chi $M_{\mathrm{w}} 7.6$ earthquake (Chang et al., 2000, 2007). Fig. 1 shows the distribution of the earthquakes of $M \geq 3.0$ between 1991 and 2006. Of all the earthquakes occurred during that time, the ChiChi earthquake was the most disastrous. It was also the best studied event, and has provided important lessons for the seismological community (e.g. Teng et al., 2001). It was preceded by a noticeable decrease in regional seismicity rate (Wu and Chiao, 2006; Chen et al., 2005). Chen (2003) also found the activation of moderate-sized earthquakes before the Chi-Chi event and discussed its important implication to the self-organizing spinodal model of earthquakes (Rundle et al., 2000). In addition, Wu and Chen (2007) reported a cycle of the seismic reversal embedded in the changes of seismicity. In this study, we examine whether there had been significant changes in the patterns of seismic activities before the Chengkung earthquake.

\section{Data}

The Central Weather Bureau Seismic Network (CWBSN) in Taiwan is responsible for monitoring regional seismic activities. The network started real-time digital recording in 1991. Currently it consists of a 


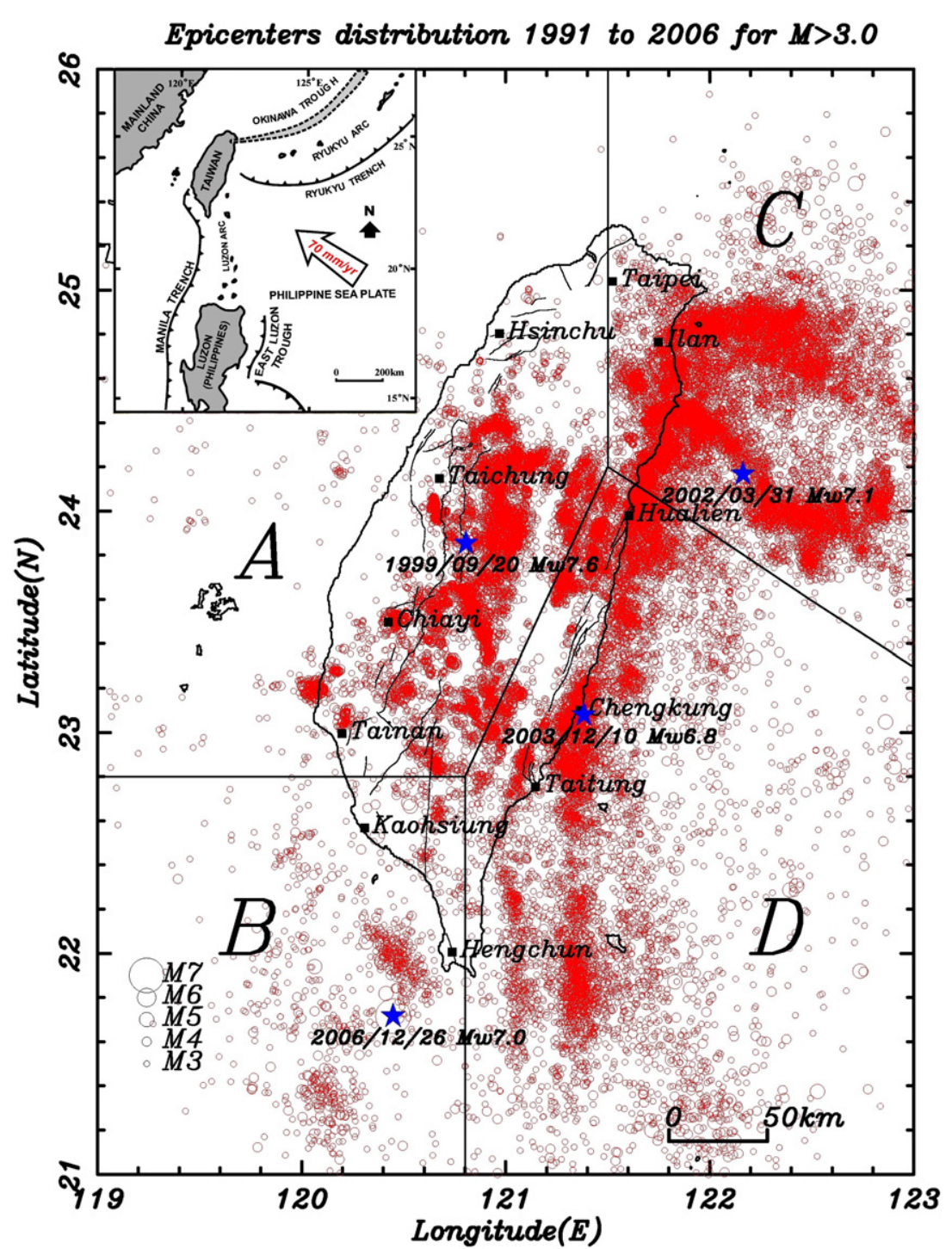

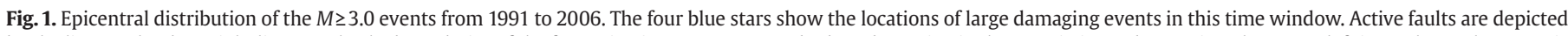

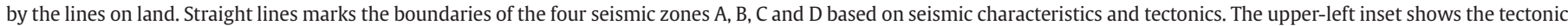
map of Taiwan region. (For interpretation of the references to color in this figure legend, the reader is referred to the web version of this article.)

central recording system with 71 telemetered stations equipped with 3-component Teledyne/Geotech S13 seismometers. Including the now retired stations, the CWBSN has a total of 90 different sites. Fig. 2(A) shows the distribution of the CWBSN stations (solid triangles). Before continuous recording started at the end of 1993, the CWBSN instruments had been operated in a triggered mode. At each station, seismic signals are digitized at 12 bits and 100 samples per second and are transmitted to the data center in Taipei via dedicated telephone lines. The network has a system for automatic earthquake detection followed by manual verification. Arrival times of $\mathrm{P}$ and $\mathrm{S}$ waves are manually picked for the determinations of earthquake location and magnitude $M_{\mathrm{L}}$ (Shin, 1993). The earthquake monitoring capability of a network can be measured by the magnitude completeness parameter, Mc, defined as the central value of the 0.2-magnitude bin with the maximum number of events within a searching distance of $25 \mathrm{~km}$. The CWBSN has greatly enhanced the earthquake monitoring capability in Taiwan with a Mc value down to about $M_{\mathrm{L}}=2.0$ since the end of 1993 (Wu and Chiao, 2006). Using the CWBSN earthquake catalog from 1994, we estimated the values of Mc in the period from 1994/01/01 to the 2003/10/09 for shallow earthquakes (focal depth $\leq 35 \mathrm{~km}$ ) and the spatial variation of Mc is displayed in Fig. 2A). The pattern of Mc variation depends on the density of the seismic stations. The Mc values for the entire inland region are 2.0 and below. The station density is higher in southern Taiwan, where the Mc values can be as low as about 1.2. Higher Mc values of 2.5 to 3.2 occur mostly in the offshore region outside of the network.

Seismicity studies demands accurate locations of earthquakes. Therefore, in this study we used the relocated CWBSN catalog by Wu et al. (2008). Wu et al. (2008) improved the CWBSN earthquake locations in three aspects: the inclusion of a large dataset of the S-P times from 680 Taiwan Strong-Motion Instrumentation Program (TSMIP) stations distributed throughout the island to complement the CWBSN's coverage of inland earthquakes; the addition of 18 Japan Meteorological Agency (JMA) stations in the southern Ryukyu Island chain to enhance the station coverage for eastern offshore events; and the adoption of the three-dimensional $\mathrm{Vp}$ and $\mathrm{Vp} / \mathrm{Vs}$ models of $\mathrm{Wu}$ et al. (2007) in predicting the travel times of $\mathrm{P}$ and $\mathrm{S}$ waves. The relocated catalog provides more accurate locations of earthquakes used in this study.

\section{Temporal variations of the number of earthquakes and the $b$-value}

In Fig. 3 are the monthly occurrence rates and the $b$-values for crustal events (focal depth $\leq 35 \mathrm{~km}$ ) in our study region from 1994 to 
2006. The monthly occurrence rates are calculated by counting events with $M_{\mathrm{L}} \geq 2.0$ in every month and then normalizing the counts to the duration of 30 days. The average occurrence rate is 881 events per 30 days with a standard deviation of 1173 events. We use a maximum likelihood approach to estimate the $b$-values (Aki, 1965). The average amounts to the value of 0.83 with a standard deviation of 0.08 .

Apart from the Chi-Chi and Chengkung earthquakes, there were two other significant events in the Taiwan region. They are the Hualien $M_{\mathrm{w}} 7.1$ earthquake on March 31, 2002, offshore east of Taiwan, and the Hengchun $M_{\mathrm{w}} 7.0$ earthquake on December 26, 2006, offshore south of Taiwan. These two earthquakes are offshore events. It is clear that periods of relatively low-seismicity emerged prior to those earthquakes, with the exception of the Hualien earthquake. Although the $b$-values didn't have significant low or high anomalies, it exhibited a consistent decreasing trend during the relatively low-seismicity period before the occurrence of the big earthquakes. Obviously, the pattern before the 2006 Hengchun event was very similar to that before the Chi-Chi earthquake. Unfortunately, our dataset does not allow for further analysis on this case. We will thus focus on the 2003 Chengkung earthquake for a more detailed examination.

\section{Seismicity rate and $b$-value changes before the Chengkung earthquake}

Before the Chengkung earthquake, the period of relatively lowseismicity and the decrease of the $b$-values lasted for about one year. The epicentral distribution of the crustal events is shown Fig. 2(B). To establish the spatial distribution of the seismicity rate and the $b$ -

(A) Magnitude Completeness 1994/01/01 to 2003/12/09

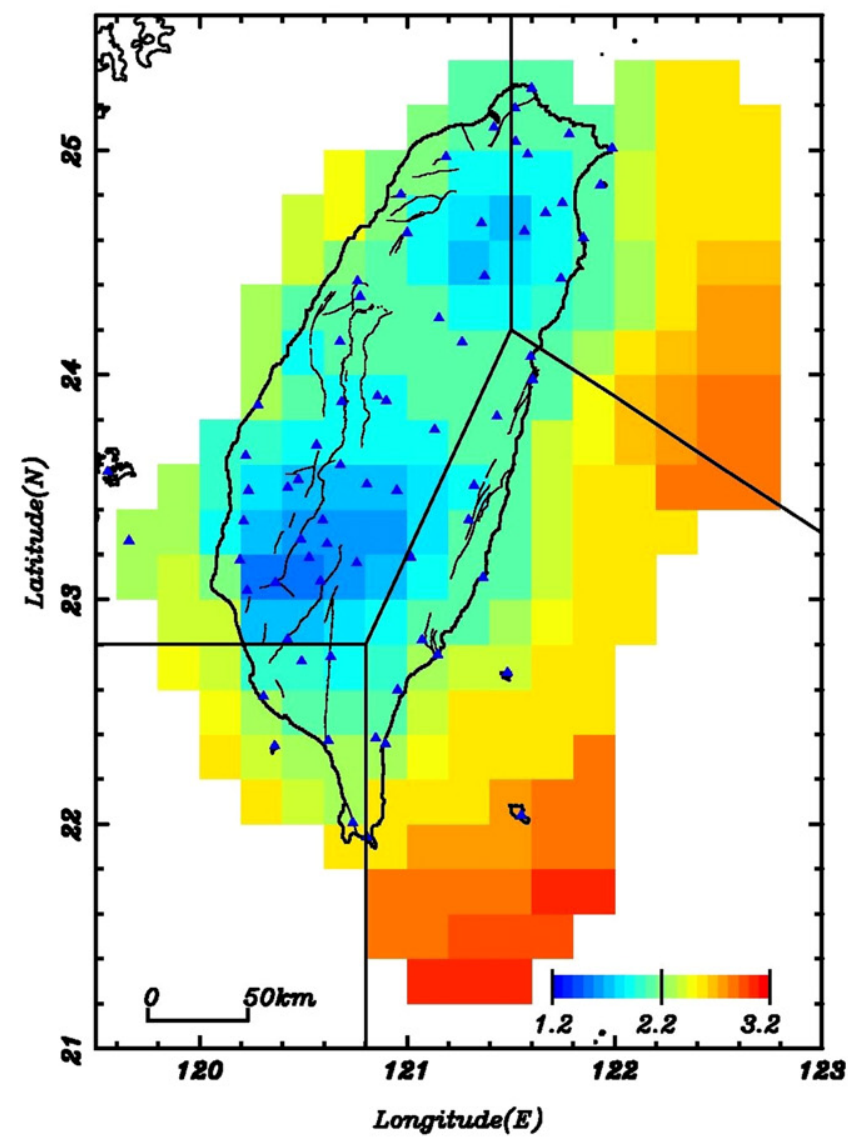

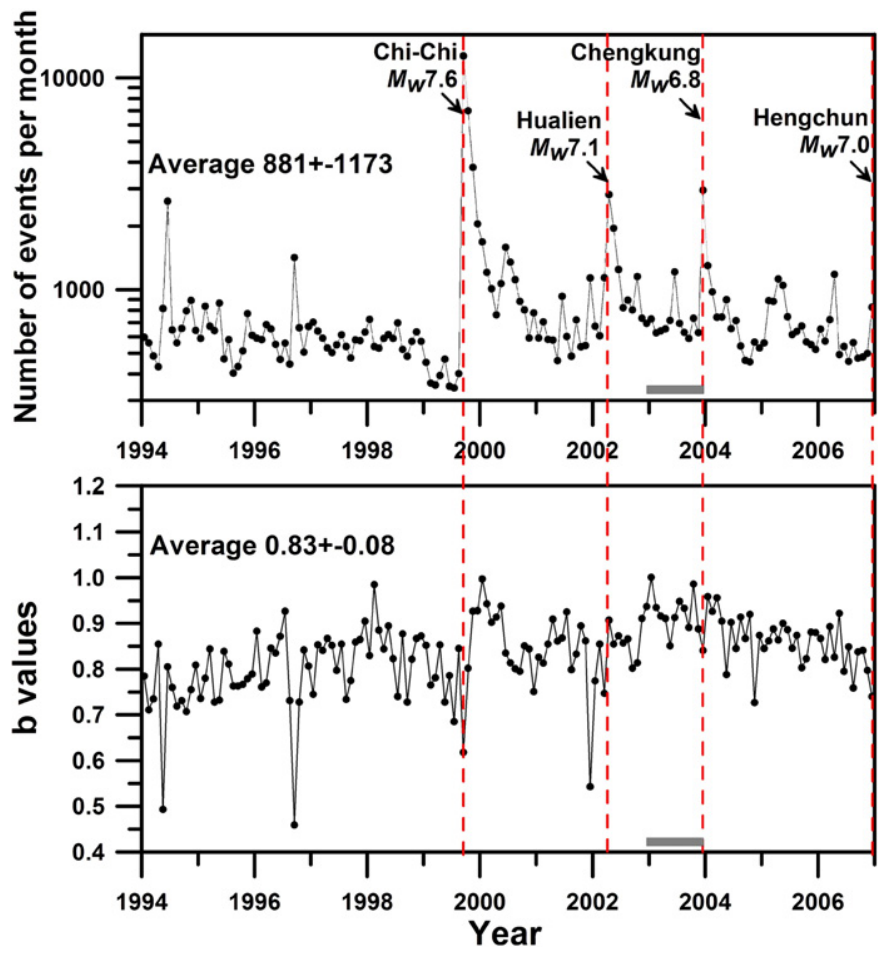

Fig. 3. Monthly numbers of events and $b$-values of earthquakes with $M_{\mathrm{L}} \geq 2.0$ from 1994 to 2006 within the study region.

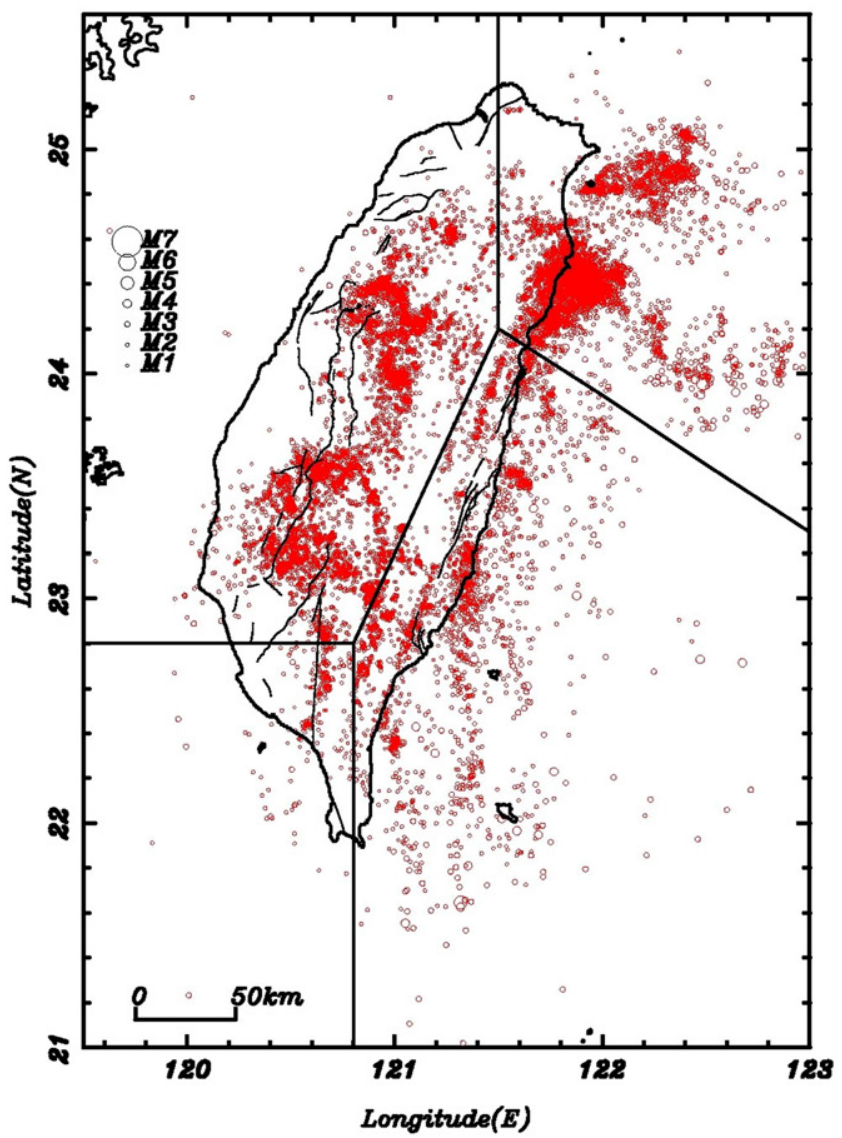

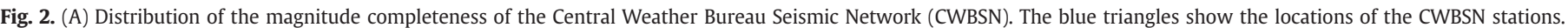

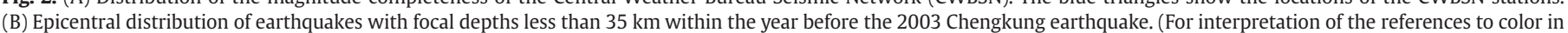
this figure legend, the reader is referred to the web version of this article.) 
(A) $Z$ values of Seismicity Rate 2002/12/10 to 2008/12/09

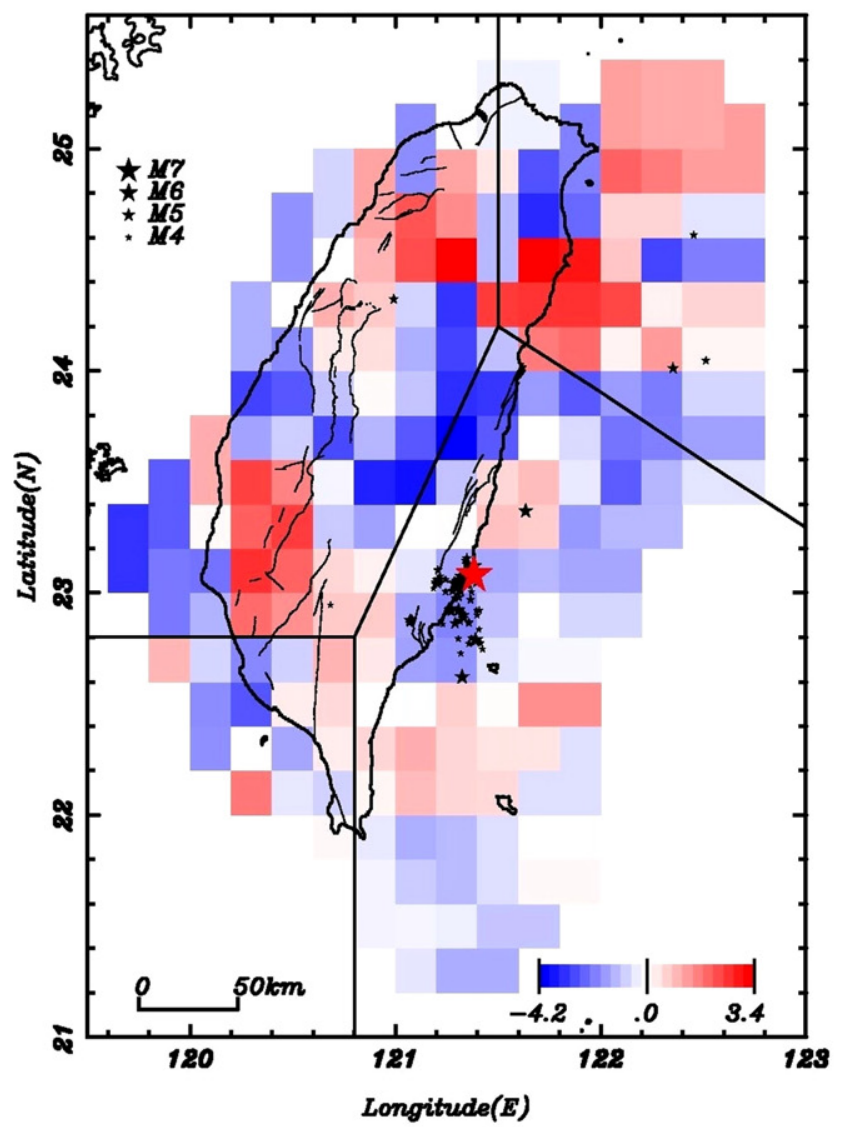

(C)

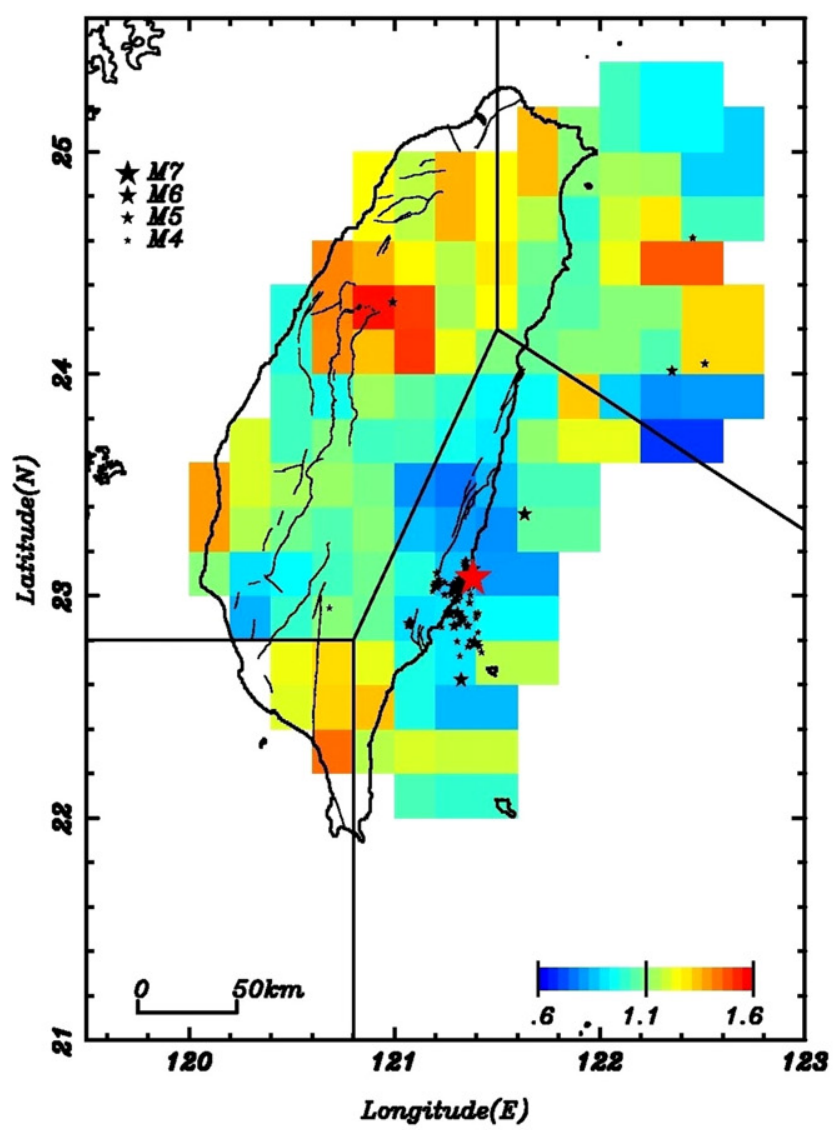

(B) $b$ values changes $2002 / 12 / 10$ to $2003 / 12 / 09$

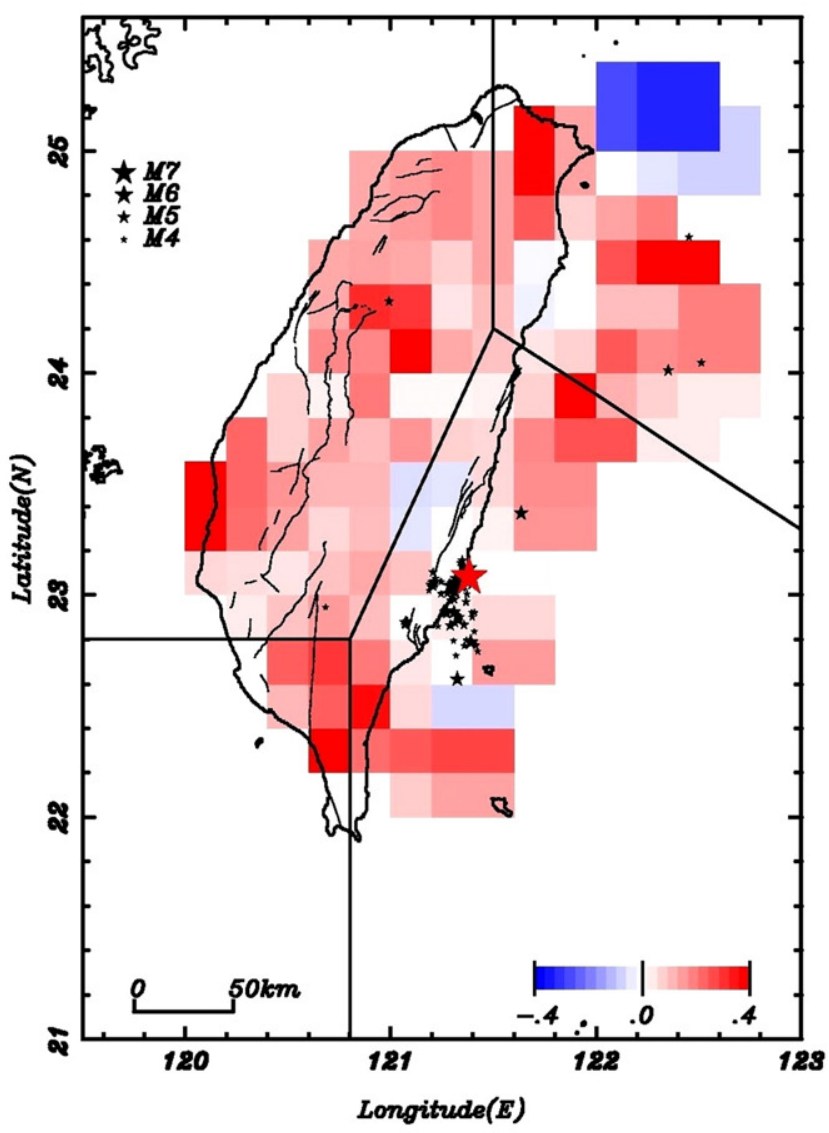

(D)

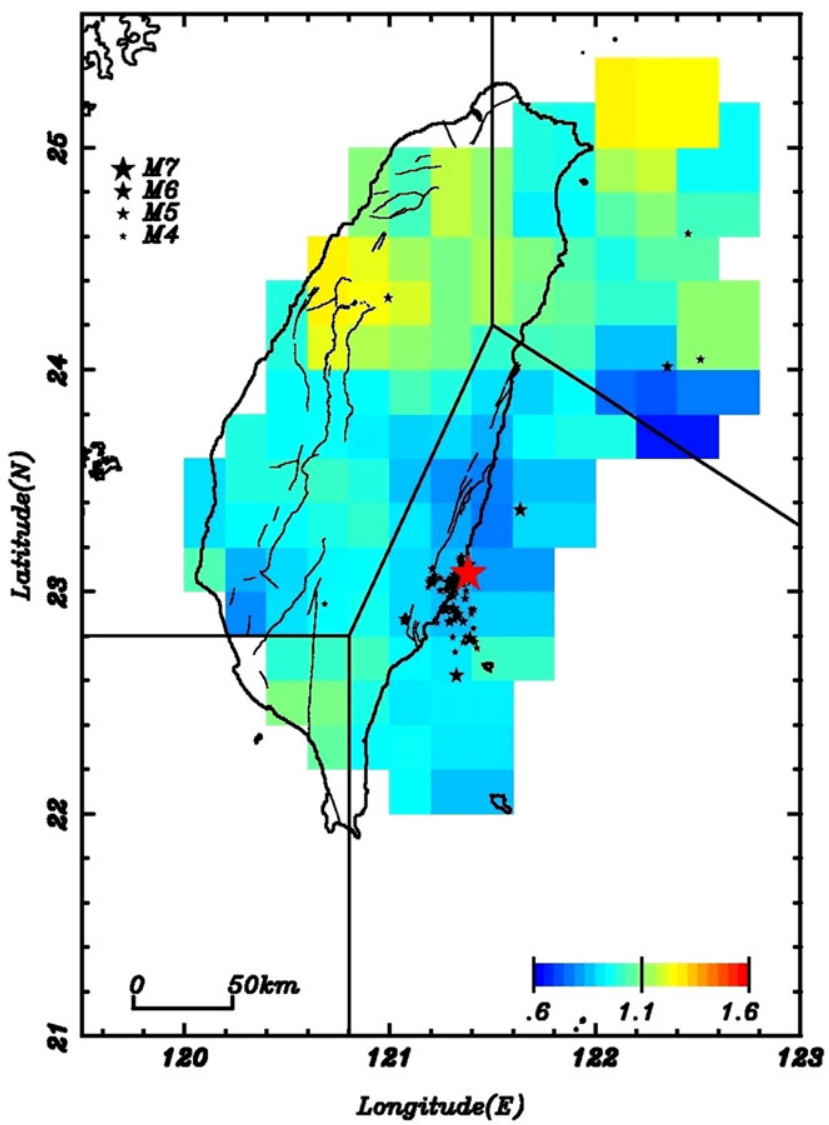


values, we used the method of standard normal deviate $Z$ test to calculate the map showing the seismic activity, which is similar to the popular ZMAP analysis (Wiemer and Wyss, 1994). First we calculated the regional $Z$-values and $b$-values for the analysis period from 2002/ $12 / 10$ to $2003 / 12 / 09$ for events with $M_{\mathrm{L}} \geq M_{\mathrm{C}}$ (Fig. 2A) and focal depths less than $35 \mathrm{~km}$ in the region bounded by $21.0^{\circ} \mathrm{N}$ to $25.5^{\circ} \mathrm{N}$ and $119.5^{\circ} \mathrm{E}$ to $123.0^{\circ} \mathrm{E}$. The spatial grid spacing is $0.2^{\circ}$, yielding a resolution radius of about $25 \mathrm{~km}$. We used a maximum likelihood approach to estimate the $b$-values (Aki, 1965) from the original catalogue. The temporal bin length is set to 60 days in the calculation the $Z$-values. For each spatial pixel, the local $Z$-value is then calculated by the following equation:

$Z(x, y, t)=\left(R-R_{0}\right) / \sqrt{\left(\sigma^{2} / n\right)+\left(\sigma_{0}^{2} / n_{0}\right)}$

where $R_{0}$ is the spatial distribution of the mean values of the background seismicity intensity, i.e. the earthquake numbers at individual pixels calculated over the entire time-span through January 1, 1994 to December 9, 2003, and $R$ is the seismicity intensity in the corresponding pixel over the analysis time window. Similarly, $\sigma_{0}$ and $\sigma$ are the standard deviations of $R_{0}$ and $R$, respectively, and $n_{0}$ and $n$ are the corresponding binning numbers. A positive $Z$-value thus indicates a rise in seismicity and a negative value a decrease. We also calculated the $b$-values over the background period and the $b$-value changes between the target and background periods.

It is important to note that the calculation of the background seismicity intensity function was conducted using the declustered catalogue while the seismicity intensity function for the analysis span was obtained from the original catalogue (Wu and Chen, 2007). Therefore this operation is different from the usual ZMAP analysis. Due to the use of the original catalogue to calculate seismicity intensity, our $Z$-values are more dominated by the active earthquake activity, especially by earthquake sequences. However, during seismic quiescence period our $Z$-value distribution has same the pattern as the ZMAP.

For the declustering algorithm, we had applied the method of spatio-temporal double-link cluster analysis to eliminate aftershocks in the earthquake catalogue. This method is similar to the single-link cluster analysis proposed by Davis and Frohlich (1991). Using the temporal and spatial linking parameters of 3 days and $5 \mathrm{~km}$, respectively, we removed the aftershocks generated from main shocks with $M_{\mathrm{L}} \geq 4.5$. Those are the linking parameters usually used for declustering the CWBSN catalogue (Wu and Chiao, 2006; Wu and Chen, 2007).

Fig. 4 shows the $Z$-values, $b$-values and $b$-value changes for the analysis period, and the $b$-values for the background period. Stars in Fig. 4 are the $M_{\mathrm{L}} \geq 4.0$ events within 30 days after the Chengkung earthquake. Most of them are within the cluster of the aftershocks of the Chengkung earthquake. The aftershock cluster may be considered as the extent of the fault rupture region of the Chengkung earthquake (Wu et al., 2006). During the analysis period, a number of regions in the western and northeastern seismic zones are still in a status of high positive $Z$-values caused by the aftershock activities following the 1999 Chi-Chi and 2002 Hualien earthquakes. Interestingly, most of southeastern seismic zone showed a decrease in seismicity with negative $Z$-values. However, there was simultaneously a significant seismicity increase marked by the positive $Z$-values in the areas surrounding the Chengkung earthquake rupture regions (Fig. 4A). This pattern had also occurred before the Chi-Chi earthquake (Wu and Chiao, 2006). The Chengkung earthquake rupture region has low $b$-values in both the analysis and background periods. In particular, the $b$-values in the source region of the Chengkung earthquake showed a slight decrease, whereas in most of the regions in Taiwan the

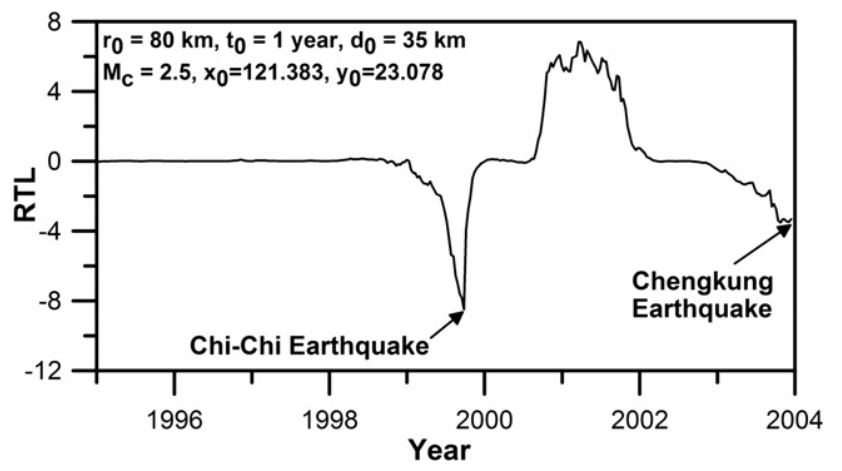

Fig. 5. Temporal variation in the RTL function at the epicenter of the Chengkung earthquake. An increase in seismicity appeared around 2001, followed by the seismic quiescence around 2003.

$b$-values were increasing. According to the $b$-values in Fig. 3, it can be recognized that in the one-year period before the Chengkung earthquake, the $b$-values are higher than in most other periods. Thus, it caused the $b$-value increase in most of the regions in Taiwan.

Following previous investigations of seismicity change by means of the Region-Time-Length (RTL) algorithm (Huang et al., 2001; Huang and Nagao, 2002; Huang, 2004; Huang, 2006a; Huang, 2006b; Huang et al., 2002; Chen and $\mathrm{Wu}, 2006)$, we have further investigated the temporal seismicity variation in the epicentral area of the Chengkung event before the main shock. The basic idea of the RTL algorithm is to assign an RTL weighting value at a given spatio-temporal grid point $(x, y, t)$, which is resulted from events occurred in a prescribed spatiotemporal window with characteristic lengths in space and time. Functionally, the RTL weight resulted from an event is greater when that event is larger in magnitude and closer to the spatio-temporal point $(x, y, t)$ under investigation. A change in RTL value means a change in seismicity rate induced by precursory activation and/or quiescence around the investigation point $(x, y, t)$. For the RTL analysis of the Chengkung earthquake, we calculated the temporal variation in the RTL function at its epicenter. Fig. 5 shows the RTL values from 1995 through the end of 2003, before the Chengkung main shock. In Fig. 5, a striking seismic activation stage can be seen around the year of 2001, which implies that the phenomenon of seismic activation probably began in 1999 because at each time step $t_{i}$ the RTL value was actually calculated from earthquakes occurred in a characteristic time-span of $\sim 2$ years before $t_{i}$. In addition, seismic quiescence can also be found around 2003 (Fig. 5), implying that the seismic quiescence started in 2001. The change in the RTL function, therefore, suggests that the epicentral area of the Chengkung event experienced a period of seismic activation followed by a period of seismic quiescence before the main shock.

\section{Discussion}

The appearance of a ring-shaped pattern of micro-earthquakes surrounding the epicenter of a future large earthquake has been called the Mogi donut (Mogi, 1969). Although the occurrences of the Mogi donut preceding several major earthquakes in Japan and China have been reported (Mogi, 1985), it has rarely occurred elsewhere. In the $Z$-value map in Fig. 4(A), we have noticed a donut-shaped zone with positive $Z$-values, implying a meaningful increase in seismicity, surrounding the Chengkung earthquake rupture region with negative $Z$-values. Such a pattern indicates an abnormal seismic quiescence in the hole of the donut and a higher than usual seismic activity in the 
outer ring. This pattern suggested that the central region could experience high stress and therefore were likely to have a large earthquake (Mogi, 1969). In addition to the Mogi donut pattern of seismic activity, there were also noticeable decreases in the $b$-values in the region surrounding the Chengkung mainshock one year before the occurrence of the earthquake (Fig. 4B). The reduction in the $b$-values was probably caused by the activity of moderate earthquakes. In other words, the precursory phenomena associated with the Chengkung earthquake very likely involved both the quiescence in the overall seismicity (the relatively silent hole of the Mogi donut in Fig. 4A) and the activation of moderate-sized events (the reduced $b$-values in Fig. 4B).

Decrease in $b$-value (e.g., Zhang et al., 1999; Wu and Chiao, 2006) before large earthquakes has been documented previously from local earthquake catalogues. The same phenomenon was also found in this study. Recently Latchman et al. (2008) analyzed the global earthquake catalogue for piecewise $b$-value gradient and reported similar results. Decrease in $b$-value may result from a decrease in the number of lowmagnitude events (Wu and Chiao, 2006) or an increase in the number of high-magnitude events (Chen, 2003; Latchman et al., 2008). This phenomenon is one of the important elements that can be helpful in earthquake forecasting and needs further study.

\section{Summary}

Using a newly obtained earthquake catalog for the Taiwan region, we have conducted an analysis of the seismic activities before the 2003 Chengkung earthquake by calculating the spatio-temporal variations of the $Z$-values and $b$-values. In the $Z$-value and $b$-value maps, we have identified the ring-shaped zone of the seismicity increase surrounding the Chengkung earthquake rupture region and the appearance of relatively low-seismicity and the $b$-value decrease in the source region before the mainshock. These so-called Mogi donut-shaped seismicity patterns may be resulted from the accommodation of the crustal material to the stress environment, which can be important observations to understand the mechanism of the occurrence of large earthquakes.

\section{Acknowledgments}

This research was supported by the Central Weather Bureau and the National Science Council of the Republic of China (NSC95-2625-Z002-028, NSC95-2119-M-002-043-MY3 and NSC95-2119-M-001063). CCC is grateful for research support from both the National Science Council (ROC) and the Institute of Geophysics (NCU, ROC).

\section{References}

Aki, K., 1965. Maximum likelihood estimate of $\mathrm{b}$ in the formula $\log \mathrm{N}=\mathrm{a}-\mathrm{bM}$ and its confidence limits. Bull. Earthq. Res. Inst. 43, 237-239.

Chang, C.H., Wu, Y.M., Shin, T.C., Wang, C.Y., 2000. Relocating the 1999 Chi-Chi Earthquake, Taiwan. Terr. Atmos. Ocean. Sci. 11, 581-590.

Chang, C.H., Wu, Y.W., Zhao, L., Wu, F.T., 2007. Aftershocks of the 1999 Chi-Chi, Taiwan, earthquake: the first hour. Bull. Seism. Soc. Am. 97, 1245-1258. doi:10.1785| 0120060184.
Chen, C.C., 2003. Accelerating seismicity of moderate-sized earthquakes before the 1999 Chi-Chi, Taiwan, earthquake: testing time-prediction of self-organizing spinodal model of earthquakes. Geophys. J. Int. 155, F1-F5.

Chen, C.C., Rundle, J.B., Holliday, J.R., Nanjo, K.Z., Turcotte, D.L., Li, S.C., Tiampo, K.F. 2005. The 1999 Chi-Chi, Taiwan, earthquake as a typical example of seismic activation and quiescence. Geophys. Res. Lett. 32, L22315.

Chen, C.C., Wu, Y.X., 2006. An improved region-time-length algorithm applied to the 1999 Chi-Chi, Taiwan earthquake. Geophys. J. Int. 166, 1144-1147.

Davis, S.D., Frohlich, C., 1991. Single-link cluster analysis of earthquake aftershocks: decay laws and regional variations. J. Geophys. Res. 96, 6336-6350.

Huang, Q., Sobolev, G.A., Nagao, T., 2001. Characteristics of the seismic quiescence and activation patterns before the $M=7.2$ Kobe earthquake, January 17, 1995. Tectonophys 337, 99-116.

Huang, Q., Nagao, T., 2002. Seismic quiescence before the $2000 \mathrm{M}=7.3$ Tottori earthquake. Geophs. Res. Lett. 29, 1578.

Huang, Q., 2004. Seismicity pattern change prior to large earthquakes - an approach of the RTL algorithm. Terr. Atmos. Ocean. Sci. 15, 469-491.

Huang, Q., 2006a. Search for reliable precursors: a case study of the seismic quiescence of the 2000 western Tottori prefecture earthquake. J. Geophys. Res. 111, B04301. doi:10.1029/2005JB003982.

Huang, Q., 2006b. Seismicity associated with the 2000 earthquake swarm in the Izu Island region. J. Asian Earth Sci. 26, 509-517. doi:10.1016/j.jseaes.2004.11.005.

Huang, Q., Öncel, A.O., Sobolev, G.A., 2002. Precursory seismicity changes associated with the Mw=7.4 1999 August 17 Izmit (Turkey) earthquake. Geophys. J. Int. 151 235-242.

Keilis-Borok, V.I., Kossobokov, V.G., 1990. Premonitory activation of seismic flow: algorithm M8. Phys. Earth Planet. Inter. 61, 73-83.

Kuochen, H., Wu, Y.M., Chen, Y.G., Chen, R.Y., 2007. 2003 Mw6.8 Chengkung earthquake and its associated seismogenic structures. J. Asian Earth Sci. 31, 332-339.

Latchman, J.L., Morgan, F.D.O., Asinall, W.P., 2008. Temporal changes in the cumulative piecewise gradient of a variant of the Gutenberg-Richter relationship, and the imminence of extreme events. Earth Sci. Rev. 87, 94-112.

Mogi, K., 1979. Two kinds of seismic gaps. Pure Appl. Geophys. 117, 1172-1186.

Mogi, K., 1969. Some features of recent seismic activity in and near Japan (2): activity before and after great earthquakes. Bull. Earthq. Res. Inst. Univ. Tokyo 47, 395-417.

Mogi, K., 1985. Earthquake Prediction. Academic Press, Tokyo.

Rundle, J.B., Klein, W., Turcotte, D.L., Malamud, B.D., 2000. Precursory seismic activation and critical-point phenomena. Pure Appl. Geophys. 157, 2165-2182.

Shin, T.C., 1993. The calculation of local magnitude from the simulated Wood-Anderson seismograms of the short-period seismograms. Terr. Atmos. Ocean. Sci. 4,155-170.

Teng, T.L., Tsai, Y.B., Lee, W.H.K., 2001. Preface to the 1999 Chi-Chi, Taiwan, earthquake dedicated issue. Bull. Seism. Soc. Am. 91, 893-894.

Tsai, Y.B., Teng, T.L., Chiu, J.M., Liu, H.L., 1977. Tectonic implications of the seismicity in the Taiwan region. Mem. Geol. Soc. China 2, 13-41.

Wang, J.H., 1998. Studies of earthquake seismology in Taiwan during the 1897-1996 period. J. Geol. Soc. Chin. 41, 291-335.

Wiemer, S., Wyss, M., 1994. Seismic quiescence before the Landers $(M=7.5)$ and Big Bear (M=6.5) 1992 earthquakes. Bull. Seism. Soc. Am. 84, 900-916.

Wu, F.T., 1978. Recent tectonics of Taiwan. J. Phys. Earth (Suppl.) 26, S265-S299.

Wu, Y.M., Chiao, L.Y., 2006. Seismic quiescence before the 1999 Chi-Chi, Taiwan Mw7.6 earthquake. Bull. Seism. Soc. Am. 96, 321-327.

Wu, Y.M., Chen, Y.G., Shin, T.C., Kuochen, H., Hou, C.S., Chang, C.H., Wu, C.F., Teng, T.L., 2006. Coseismic vs. interseismic ground deformations, faults rupture inversion and segmentation revealed by 2003 Mw 6.8 Chengkung earthquake in eastern Taiwan. Geophys. Res. Lett. 33, L02312.

Wu, Y.M., Chen, C.C., 2007. Seismic reversal pattern for the 1999 Chi-Chi, Taiwan, Mw 7.6 earthquake. Tectonophysics 429, 125-132.

Wu, Y.M., Chang, C.H., Zhao, L., Shyu, J.B., Chen, Y.G., Sieh, K., Avouac, J., 2007. Seismic tomography of Taiwan: improved constraints from a dense network of strong motion stations. J. Geophys. Res. 112, B08312. doi:10.1029/2007JB004983.

Wu, Y.M., Chang, C.H., Zhao, L., Teng, T.L., Nakamura, M., 2008. A comprehensive relocation of earthquakes in Taiwan from 1991 to 2005. Bull. Seism. Soc. Am. 98, 1471-1481. doi:10.1785/0120070166.

Wyss, M., Habermann, R.E., 1988. Precursory seismic quiescence. Pure Appl. Geophys. 126, 319-332. doi:10.1007/BF00879001.

Yu, S.B., Chen, H.Y., Kuo, L.C., 1997. Velocity field of GPS stations in the Taiwan area Tectonophysics 274, 41-60.

Zhang, G., Zhu, L., Song, X., Li, Z., Yang, M., Su, N., Chen, X., 1999. Predictions of the 1997 strong earthquakes in Jiashi, Xinjiang, China. Bull. Seism. Soc. Am. 89, 1171-1283. 